\title{
A rare complication after circumcision: Keloid of the penis
}

\author{
Fikret Erdemir · Ozgur Gokce · Oner Sanli • Ates Kadioglu • Bekir Suha Parlaktas • \\ Nihat Uluocak · Isin Kilicaslan
}

Published online: 6 July 2007

(C) Springer Science+Business Media B.V. 2007

\section{Erratum to: Int Urol Nephrol (2006) 38(3-4):609-611 DOI 10.1007/s11255-006-0021-6}

The information about the authors and their affiliations was incomplete. The correct list of authors and their affiliations are shown above and below.

Fikret Erdemir: Department of Urology, Istanbul Faculty of Medicine, Istanbul University, Istanbul, Turkey. E-mail: fikreterdemir@mynet.com

Ozgur Gokce: Department of Urology, Istanbul Faculty of Medicine, Istanbul University, Istanbul, Turkey

Oner Sanli: Department of Urology, Istanbul Faculty of Medicine, Istanbul University, Istanbul, Turkey

Ates Kadioglu: Department of Urology, Istanbul Faculty of Medicine, Istanbul University, Istanbul, Turkey
Bekir Suha Parlaktas: Department of Urology, Istanbul Faculty of Medicine, Istanbul University, Istanbul, Turkey

Nihat Uluocak: Department of Urology, Istanbul Faculty of Medicine, Istanbul University, Istanbul, Turkey

Isin Kilicaslan: Department of Pathology, Istanbul Faculty of Medicine, Istanbul University, Istanbul, Turkey

The online version of the original article can be found under doi: 10.1007/s11255-006-0021-6.

F. Erdemir $(\bowtie) \cdot$ O. Gokce · O. Sanli ·

A. Kadioglu · B. S. Parlaktas · N. Uluocak

Department of Urology, Istanbul Faculty of Medicine, Istanbul University, Istanbul, Turkey

e-mail: fikreterdemir@mynet.com

I. Kilicaslan

Department of Pathology, Istanbul Faculty of Medicine,

Istanbul University, Istanbul, Turkey 